\title{
Effect of drying-wetting cycles on aggregate breakdown for yellow-brown earths in karst areas
}

Jie Xu, Yiqun Tang ${ }^{*}$ and Jie Zhou

\begin{abstract}
Background: Drying and rewetting process, frequently occurred during climatic changes, is an important process in soil aggregate slacking and dissolution. The severer interference of human activities on global climate makes the extreme climate scenarios like drought and rainstorm occur frequently. Therefore, there is necessity to further our understanding on the impact of the drying-wetting cycles and initial water content on the breakdown of soil aggregates. The typical yellow-brown earth composed of water-stable and water-unstable aggregates is selected. Variations of water-stable aggregate size distributions after drying-wetting cycles are measured by wet sieving, under variable initial water content and cycles respectively.

Results: Drying-wetting cycles cause a significant aggregate slaking, especially within the first two cycles. After that, most aggregates show more slacking resistant. The variation curves of the proportion of water-stable aggregates with the size 1-5 mm shows a coexistence of slaking process and supplement. The critical initial water content (about 24\%) and turning point (with the aggregate size of $0.3 \mathrm{~mm}$ ) are proposed to describe the effects of initial water content on size distribution of water-stable aggregates. Overall, the increase of initial water content strengths the water stability. In addition, the mathematical model for the relative leakage ratio based on the drying-wetting cycle, initial water content and size distribution are established.

Conclusions: The findings reported in this paper may be capable of supporting the intensive study for the breakdown mechanism and assessing the leakage potential under the influence of climate change. However, there exists a certain mismatch between the drying-wetting cycles in the tests and in practice, mainly in the frequency and intensity, which should be paid more attention.
\end{abstract}

Keywords: Drying-wetting cycles, Yellow-brown earths, Water stability, Aggregate breakdown, Relative leakage ratio

\section{Background}

Karst topography is a landscape formed from the dissolution of soluble rocks such as limestone, dolomite, and gypsum. It is vulnerable to climate change and human activities (Yuan, 1996), and thus is considered as one of the main eco-sensitive zones. Karst topography covers an area of approximately 22 million square kilometers, accounting for about $15 \%$ of the land area. The karst topography mainly locates in lower latitudes, among which the centralized karsts are mainly distributed in

* Correspondence: $1210021 @$ tongji.edu.cn

Department of Geotechnical Engineering, Tongji University, Shanghai 200092, China central and southern Europe, eastern North America and southwest China. (Fig. 1).

The karstification can induce land degradation, vegetation coverage loss, excess soil erosion, and the karst rocky desertification eventually (Wang et al., 2004). All these conditions lead to severe pressure on geo-disaster reduction and social resilience to disasters. As the most predominant process during the formation of karst rocky desertification, large amounts of studies have documented the aspects of soil erosion. Lal (2003) described the soil erosion process as a four-stage process involving detachment of particles, breakdown of aggregates, transport and redistribution of sediments over the landscape and deposition in depressional sites or aquatic ecosystems. Foster (1982), Hogarth et al. (2004), Rouhipour et

\section{Springer Open}

(c) The Author(s). 2017 Open Access This article is distributed under the terms of the Creative Commons Attribution 4.0 International License (http://creativecommons.org/licenses/by/4.0/), which permits unrestricted use, distribution, and reproduction in any medium, provided you give appropriate credit to the original author(s) and the source, provide a link to the Creative Commons license, and indicate if changes were made. 


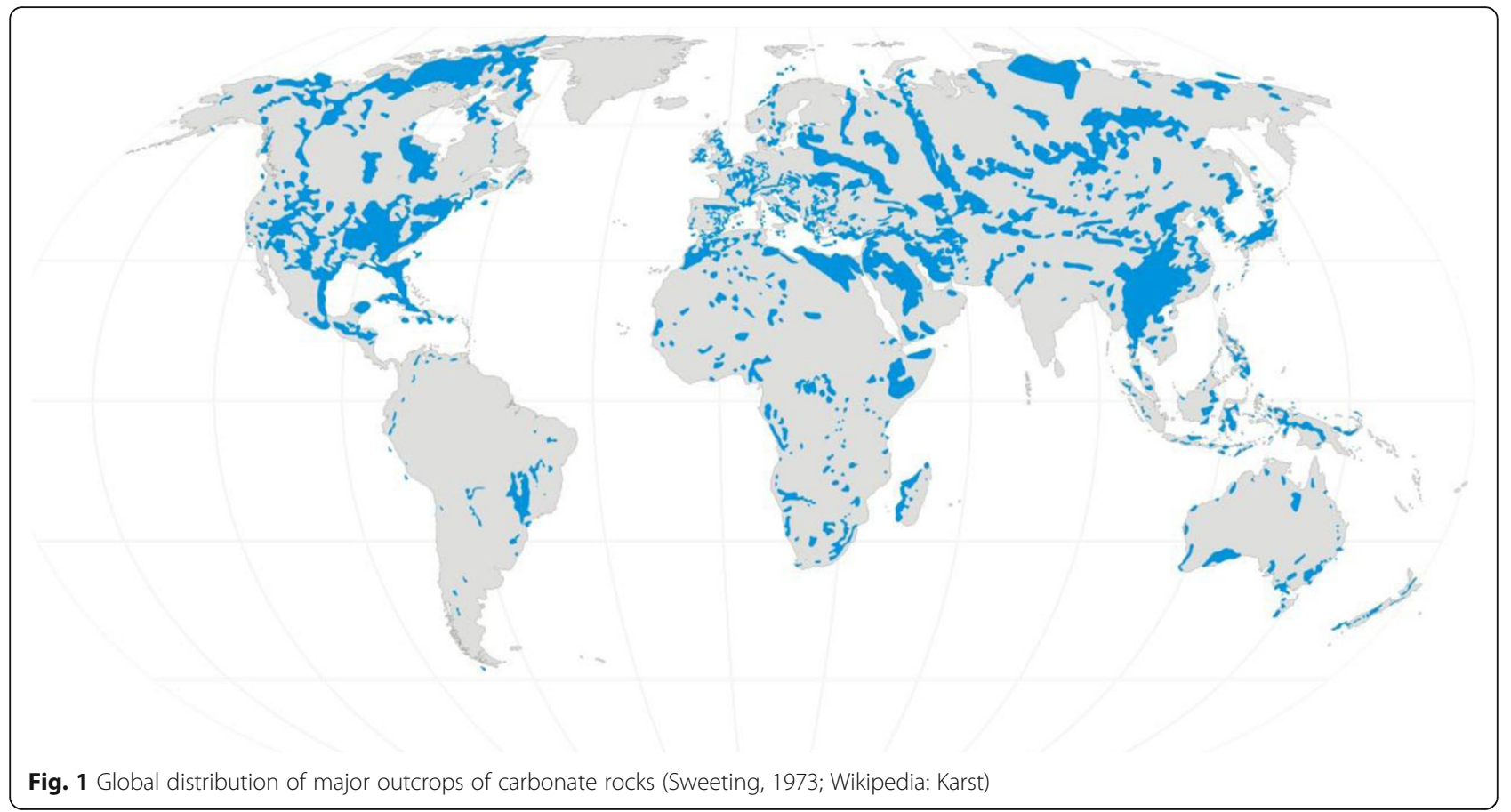

al. (2006), Walker et al. (2007), An et al. (2012) and Parlange et al. (2012) have conducted model, mathematical and simulated methods to investigate the impacts of rainfall on soil erosion. However, literatures concerning the mechanisms of water-induced soil erosion are not expressive. Tabeda and Tomita (1972) studied the mechanism of soil erosion by correlating soil erosion with rainfall intensity based on the energy of raindrops. Fujiwara and Yamamoto (1981) searched the mechanism of soil erosion under simulated rainfall. Owoputi (1994) considered mechanism of sediment detachment in the soil erosion process. Relevant indicators of vast soil degradation and erosion include texture and porosity spoilage (Figueiredo et al., 1999; Jankauskas et al., 2008), water retention capacity decline (Ye et al., 2011) and soil leanness accompanied by chemical and biologic characteristics degradation (de Paz et al., 2006) have also been studied. Based on the analysis of the indicting parameters, several attempts at assessing and evaluating soil erosion have been made including those by Olson and Wischmeier (1963), Rose et al. (1983), Smith et al. (1999), Kheir et al. (2008), Febles-González et al. (2012), Tang et al. (2015), and by Nearing et al. (1990), Shelton and Wall (1998) and Feeser and O'Connell (2009) referring to some predictions.

The yellow-brown earths, forming on the Quaternary red clay or weathered material of limestone in hot, humid and rainy climate conditions in Guizhou karst areas, are viewed as the main body of soil erosion inherently and considered to be problematic in poor water- holding capacity, unstable structures, and even lean crop productivity (Gao and $\mathrm{Li}, 2007$ ). As the basic unit of soil structure of the yellow-brown earth, the stability of aggregate is one of the most important factors controlling soil erodibility (Duiker et al., 2001). Soil aggregates are formed by the primary soil particles and soil cemented materials with the coagulation, cementation and cohesive actions, the stability of which is an important indicator for the soil quality evaluation. According to the different ways to destroy the soil aggregates, the stability of soil aggregates can be divided into mechanical stability, water stability, chemical stability, acidic and basic stability and biostability (Domżł et al., 1993). Water stability can be defined as the property and capacity of soil aggregates to resist hydraulic damage, and this stability may include wet aggregate stability (macro-aggregate stability $>250 \mu \mathrm{m}$ ) and dispersible clay (micro-aggregate

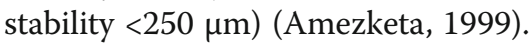

As the important indicator of soil erosion-resistance in the areas with rich runoff, the water stability of soil aggregates has been received considerable attention. Two main groups of factors affecting soil aggregate stability can be considered: soil primary characteristics or internal factors like clay mineralogy (Reichert et al., 2009) and organic matter (Jozefaciuk and Czachor, 2014), and external factors to the soils such as dryingwetting cycles, freezing-thawing cycles (Dagesse, 2012), biological factor (Jastrow and Miller, 1991), tillage (Bartlová et al., 2015) and so on. In nature, most surficial soils are subjected to drying-wetting cycles due to 
alternative rainfall and evapo-transpiration. During these cycles most of the properties of soils, especially their strength and hydraulic stability, are severely affected and as a result crack propagation and stability failure occur (Kemper et al., 1985; Denef et al., 2001a,b; Peng et al., 2007). However, the effects of drying-wetting cycles on water stability of soil aggregates have been considered to be variable. Pires et al. (2007) suggested that wettingdrying cycles can be used to repair some structurally damaged soils. Soulides and Allison (1961), Tisdall et al. (1978) found that drying-wetting cycles decreased the water-stability of soil aggregates. Hofman (1976) obtained a contrary result that the aggregate instability of aggregates sieved immediately after sampling was greater than that obtained when the soil was first air-dried and then rewetted to its original water content. In the research of Utomo and Dexter (1982), wetting and drying first increased the water stability of aggregates disturbed by tillage to a maximum value and then decreased it with the further wetting and drying.

Through the above literature review, the following potential problems arise. The effects of drying and rewetting process on soil aggregate stability are inconsistent, largely depending on soil type, percent of stabilizer, test methods and curing conditions, as forementioned. Thus, the effects on the erodible earths in karst areas, especially in the slacking process, the changes of the aggregates with different sizes and the water stability with further cycles, need to be studied. In addition, the role of the initial water content in the effects of drying-wetting cycles on the water stability has not been studied. For the quantitative assessment of soil leakage potential, Igwe et al. (1995) listed six aggregate indices to predict soil leakage potential. However no attempts have focus on the soil leakage potential considering the drying-wetting cycles and the initial water content.

Therefore, the objective of this study was $(i)$ to describe the slaking behavior of a yellow-brown earth depending on variable drying and rewetting processes, (ii) to present the effect of the initial water content on size distribution of water-stable aggregates and (iii) to relate leakage potential to the drying-wetting cycles and initial water content.

\section{Methods}

\section{Regional geological and hydrogeological conditions}

The study area is located in the upper Yangtze fold belt of Yangtze paraplatform. It belongs to the southeastern limb of Puding synclinorium and northwestern limb of Guandingzhuang anticline, the hinges of which are wide and flat. The dip angles of the strata range among $6^{\circ}-$ $25^{\circ}$, and the tectonic lines are in the northeastern direction and are almost parallel (Fig. 2c). The development of landforms, valleys, underground rivers (such as Chenqi and Changchong underground river) are obviously affected and controlled by above tectonic characteristics. The joints and fissures are widely distributed in variously lithologic strata, with close relations to the folds, faults and stress fields. The widely formed $\mathrm{X}-$ shaped joints are $35^{\circ}-50^{\circ}$ and $305^{\circ}-320^{\circ}$ with the dip angle greater than $60^{\circ}$.

The strata in the research area are mainly composed of post-Triassic limestone, dolomite and loose deposits. Soil parent material is Quaternary red clay. The soil type contains yellow-brown earth, red-brown earth and limestone soil with soil texture of silty clay, silty clay loam and clay loam. The surface soil is thin and poor in continuity, the average thickness of which is only 10$30 \mathrm{~cm}$ (Fig. 2d). It lacks intermediate transition layer between the lower parent rock and the surface soils. The geological structure shows the two-layer structure (carbonate rock and residual cohesive soil).

Due to the lithology and tectonics of carbonate rocks, the groundwater system in the research area is fully developed in limestone $\left(\mathrm{T}_{2} \mathrm{~g}^{2}\right)$, and is mainly along the northwest tectonic fissure. The thickness of the vertical seepage zone is small. The groundwater depth is generally $3-10 \mathrm{~m}$ and the average hydraulic gradient is about $7 \%$. The surface water system is not complete, and is mostly composed of closed depressions, sinkholes and karst springs. Generally, the lakes and springs are the seasonal ones.

\section{Materials - Physical and mechanical properties of yellow- brown earths}

In this research, the fine-grained soil was obtained from a site near Chenqi of Puding town in Guizhou province, China $\left(26^{\circ} 15^{\prime} 36^{\prime \prime}-26^{\circ} 15^{\prime} 56^{\prime \prime} \mathrm{N} ; 105^{\circ} 43^{\prime} 30^{\prime \prime}\right.$ $\left.105^{\circ} 44^{\prime} 42^{\prime \prime}\right)$. According to Köppen climate classification the climate of the research area is of the Cf type - humid subtropical monsoon climate. Average values for air temperature, rainfall, and relative humidity are $14.2{ }^{\circ} \mathrm{C}$; $1336 \mathrm{~mm}$ per year; and $80 \%$, respectively. The dry season covers November - April and the rainy season covers May - October with the rainfall accounting for more than $80 \%$ of the whole year, forming the climatic characteristic of drought in spring/autumn and flood in summer. Entering the twenty-first century, the number of days of rainstorm and frequent of short-time heavy rain both have increased in summer. In spring and autumn, the temperature increases obviously, causing greater evaporations and severer drought. Fig. 3 shows the precipitation (wetting) and evaporation (drying) between May and September in 2008, 2013 and 2015. It can be seen from the figure that the intensity of precipitation and evaporation increase and the frequent of drying-wetting variation becomes higher with time. 


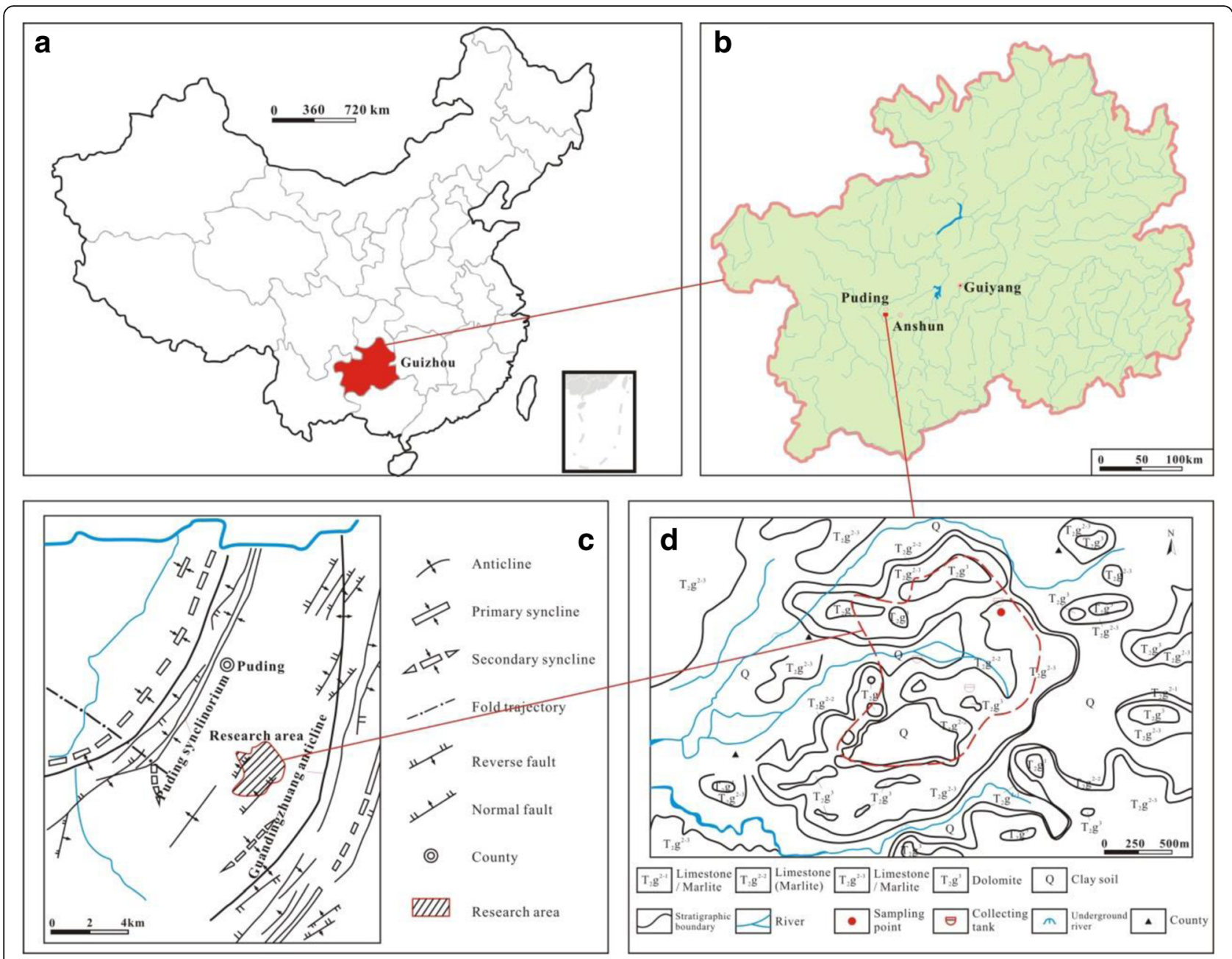

Fig. 2 Location of study area: (a) Location of Guizhou province in China; (b) Location of research area; (c) Geological structure of research area; (d) Karst geological map of research area

The soil texture is yellow-brown earth (yellow soillike, slightly red and named yellow-brown earth thereinafter) with high clay content, low organic matter content and rich inorganic colloid. It has the properties of strong bonding capacity, poor permeability and poor resistance to erosion. The mineralogy is predominantly consisted of primary mineral (quartz-35.65\%, feldspar-14.55\%) and secondary clay mineral (illite26.4\%, montmorillonite-15.0\%, Vermiculite-5.5\%) (Chen et al., 2010). Samples were taken at a depth of about $(1.5-3.0 \mathrm{~m})$ below the ground surface. Laboratory tests such as Atterberg limits, specific gravity, hydrometer analysis and compaction were performed. Table 1 presents some indices and engineering properties of the soil. The grain size distribution was $9.82 \%$ sand, $47.55 \%$ silt and $42.63 \%$ clay (Fig. 4). Based on the Casagrande plasticity chart and according to the Unified Soil Classification System (USCS), the soil was classified as silty clay.

\section{Wet sieving method}

In this paper, the water stability of soil aggregates was measured considering the effects of drying-wetting cycles and the initial water content. Therefore, the soil samples were divided into two series. Series I were the samples with the field-moist content affected by drying-wetting cycles of different cyclic numbers in five replicates. Series II were the samples with different initial water contents. In series I, $100 \mathrm{~g}$ of field-moist soil aggregates were subjected to drying-wetting cycles with the cyclic period of $192 \mathrm{~h}$ respectively. In series II, the equivalent of $100 \mathrm{~g}$ of soil aggregates with the initial water contents of $5.08 \%, 14.51 \%, 24.73 \%, 29.68 \%, 37.52 \%$ were prepared by the air-dried method.

A modification of the method of Yoder (1936) was used to measure the water stability of aggregates by wet sieving. $50 \mathrm{~g}$ of pre-prepared soil aggregates from series I or II were broken up to pass through a set of five sieves having 5.0, 2.0, 1.0, 0.5 and $0.25 \mathrm{~mm}$ aperture 


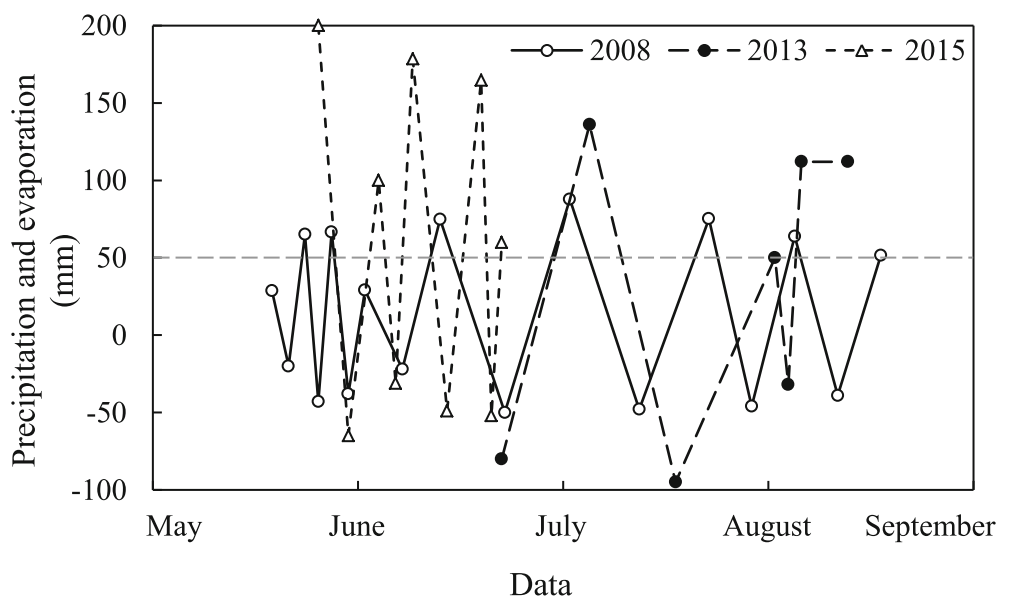

Fig. 3 Precipitation and evaporation in 2008, 2013 and 2015 (after online of Guizhou weather)

mesh respectively. The water level was adjusted so that the aggregates on the upper sieve were just submerged at the highest point of oscillation. The oscillation rate was 30 cycles per minute, the amplitude of the sieving action was $4.0 \mathrm{~cm}$ and the period of sieving was $10 \mathrm{~min}$. The sieved materials remained in the five sieves and the part through all the sieves were selected and oven-dried respectively for at least $8 \mathrm{~h}$. By weighting the six parts of dried materials, the mass percentage of soil aggregates in the range of $>5,5-2,2-1,1-0.5,0.5-0.25$, and $<0.25 \mathrm{~mm}$ can be determined respectively.

\section{Drying and wetting cyclic test}

To describe the effects of the drying-wetting cycles on aggregate breakdown and water stability of aggregates, the yellow-brown earth samples were subjected to several drying-wetting cycles. In the present study, 10 drying-wetting cycles were applied. Each cycle was consisted of $96 \mathrm{~h}$ drying of the soil samples by air dry oven with $40{ }^{\circ} \mathrm{C}$ (Relative Humidity - 34\%), and $96 \mathrm{~h}$ wetting by immersing the soil samples in water at room temperature of $20{ }^{\circ} \mathrm{C}$. From the climatic changes in Fig. 3 we can know that the interval between two precipitations is approximately $7-10 \mathrm{~d}$. Thus, we determine the duration of each drying-wetting cycle as $8 \mathrm{~d}$. In drying period, the surface temperature under direct sunshine is about $40{ }^{\circ} \mathrm{C}$ and the air dry oven is used to make the air-drying occur sufficiently slowly and tenderly so as to decrease the influence at most. In rewetting process, we apply the immersing method, which is not as violent as in nature. So we reasonably extend the rewetting duration, which should be improved in the following research in order to restore the real field conditions as far as possible. The wet sieving was applied to the subsamples in the wetting state of the first, second, fifth and tenth cycles to obtain the mass contents of the water-stable aggregates.

\section{Results and discussion Water stability of soil aggregate}

Based on the previous researches on the water stability of aggregates, the following characteristic parameters are applied to describe the water stability of the soil aggregates in this study. Generally, the mass percent contents of soil aggregates with the size greater than $0.25 \mathrm{~mm}$ or $5 \mathrm{~mm}$ after wet sieving are used as the evaluation index for the water stability, which can be symbolled as $W_{0.25}$ and $W_{5 S A_{5}}$.

$$
\begin{aligned}
& W_{0.25}=W_{d>0.25} / W_{0} \times 100 \% \\
& W S A_{5}=W_{d>5} / W_{0} \times 100 \%
\end{aligned}
$$

where, $W_{\mathrm{d}}>0.25$ and $W_{\mathrm{d}}>5$ are the mass of the waterstable aggregates with the size greater than $0.25 \mathrm{~mm}$ and $5 \mathrm{~mm}$ respectively; $W_{0}$ is the mass of the total aggregates.

\begin{tabular}{|c|c|c|c|c|c|c|}
\hline Property & $\begin{array}{l}\text { Water content } \\
w(\%)\end{array}$ & $\begin{array}{l}\text { Density } \\
\rho\left(\mathrm{g} / \mathrm{cm}^{3}\right)\end{array}$ & $\begin{array}{l}\text { Void ratio } \\
e\end{array}$ & $\begin{array}{l}\text { Liquid limit } \\
w_{\mathrm{L}}(\%)\end{array}$ & $\begin{array}{l}\text { Plastic limit } \\
W_{P}(\%)\end{array}$ & $\begin{array}{l}\text { Saturation } \\
\mathrm{S}_{\mathrm{r}}(\%)\end{array}$ \\
\hline$\overline{M a x}$ & 38.86 & 1.837 & 1.45 & 40.12 & 24.42 & 85.68 \\
\hline Min & 33.24 & 1.540 & 1.02 & 35.64 & 20.10 & 73.84 \\
\hline Ave & 37.52 & 1.684 & 1.34 & 39.87 & 22.18 & 80.89 \\
\hline
\end{tabular}

Table 1 Physical property indexes of intact yellow silty clay 


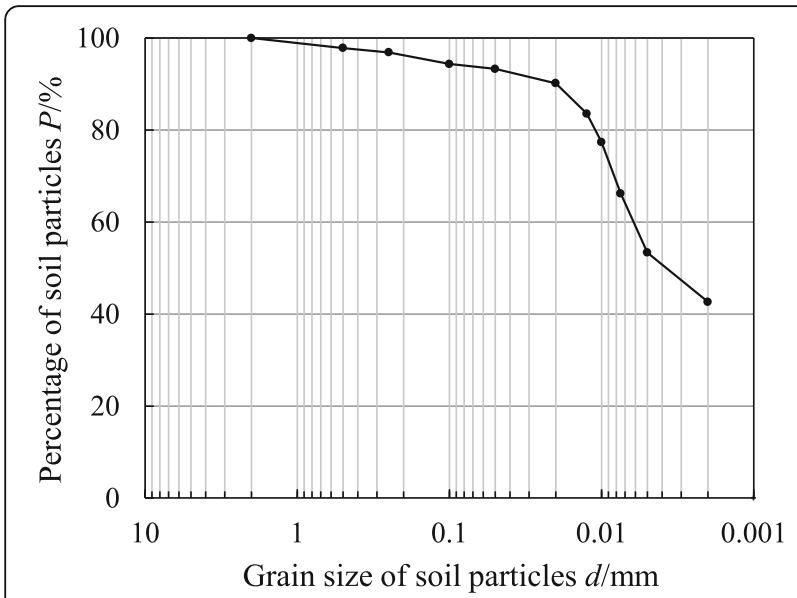

Fig. 4 Distributions of the grain size of the yellow-brown earth in karst areas

Mean weight diameter $(M W D)$ and geometric mean diameter $(G M D)$, reflecting the size distribution of the water-stable aggregates after the slaking behavior, are calculated by the weighted average of the mass and diameter parameters of soil aggregates with different agglomerates (Van Bavel, 1949; Gardner, 1956). Among which, the geometric mean diameter is based on the assumption that the size distribution of the water-stable aggregates conforms to the logarithmic normal distribution.

$$
\begin{aligned}
& M W D=\sum_{i=1}^{n} \bar{x}_{i} w_{i} / \sum_{i=1}^{n} w_{i} \\
& G M D=\operatorname{Exp}\left(\sum_{i=1}^{n} w_{i} \ln \bar{x}_{i} / \sum_{i=1}^{n} w_{i}\right)
\end{aligned}
$$

where, $\bar{x}_{i}$ is the average diameter of the $i^{\text {th }}$ aggregates; $w_{i}$ is the mass percent content of the $i^{\text {th }}$ aggregates.

The slaking ratio of the water-stable aggregate is defined as the ratio of the water-unstable aggregates and the total aggregates, measured by dry and wet sieving jointly. Generally, the slaking ratios of the water-stable aggregates greater than $0.25 \mathrm{~mm}\left(S R_{0.25}\right)$ and $5 \mathrm{~mm}$ $\left(S R_{5}\right)$ are applied to evaluate the degree of breakdown during wet sieving.

$$
\begin{aligned}
& S R_{0.25}=\frac{m_{d(d>0.25)}-m_{w(d>0.25)}}{m_{d(d>0.25)}} 100 \% \\
& S R_{5}=\frac{m_{d(d>5)}-m_{w(d>5)}}{m_{d(d>5)}} 100 \%
\end{aligned}
$$

where, $m_{d(d>0.25)}$ and $m_{w(d>0.25)}$ are the mass percent content of the aggregates with the size greater than $0.25 \mathrm{~mm}$ by dry and wet sieving respectively; $m_{d(d>5)}$ and $m_{w(d>5)}$ are the mass percent content of the aggregates with the size greater than $5 \mathrm{~mm}$ by dry and wet sieving respectively.

\section{Impact of drying-wetting cycles}

In order to explore the effects of drying-wetting cycles on the water-stable aggregates, the particle size distributions of water-stable aggregates without cycles and after $1,2,5$ and 10 times of drying-wetting cycles are listed in Table 2. The corresponding characteristic parameters of water-stable aggregates are listed in Table 3.

The size distributions of water-stable aggregates after varied drying-wetting cycles are shown in Fig. 5a. It can be seen from the figure that the peak of the size distribution curves moves in the direction of size decreasing with the increasing of drying-wetting cycles, which means that the water-stable aggregates crack into finer ones. Except for the sample without affected by the drying-wetting cycles, the size distributions of water-stable aggregates have the similar shapes, namely the gradation of aggregates will not change thoroughly with the increase of cycles.

The difference in the percent content of oven-dried aggregates in different soil samples may not be significant, but the contents of water-stable aggregates vary a lot. Therefore, the proportion of water-stable aggregates at each size range can better reflect the quality of soil aggregates. The relationships between the mass percent content of water-stable aggregates in different size range and the drying-wetting cycles are illustrated in Fig. 5b. With the increase of drying-wetting cycles, the percentage of the water-stable aggregates in the size range of $5-10 \mathrm{~mm}$ decreases obviously and the initial two cycles has the most violent effect on the disintegration of aggregates, which is consistent with the result by Denef et al. (2001a,b). After 10 times cycles, the aggregates in the size range of $5-10 \mathrm{~mm}$ remain almost no residue. Due to the supplement from the disintegration of the aggregates $(5-10 \mathrm{~mm})$ in the first cycle, the proportion of the aggregates $(2-5 \mathrm{~mm})$ increases slightly. After that period, the proportion of the aggregates $(2-5 \mathrm{~mm})$ decreases and remains almost no residue eventually. For the aggregates in the diameter of 1-2 mm, drying-wetting cycles first increase the proportion slightly; after this maximum, further drying-wetting cycles decrease the proportion. On the whole, with the further drying-wetting cycles, the proportion of the aggregates $(1-2 \mathrm{~mm})$ shows almostly no change. We speculate that there are two possibilities: one is that the supplement from slaking of greater aggregates and the slaking of aggregates with the size of 1-2 $\mathrm{mm}$ reach the equilibrium state; another is the coexistence of breakdown of larger water-stable aggregates and reunion of smaller water-stable aggregates 
Table 2 The distribution of grain size of soil aggregates under drying-wetting cycles

\begin{tabular}{lllllll}
\hline D-W cycles & \multicolumn{4}{l}{ Mass percent content of soil aggregates in each size range (\%) } \\
\cline { 2 - 7 } & $5-10 \mathrm{~mm}$ & $2-5 \mathrm{~mm}$ & $1-2 \mathrm{~mm}$ & $0.5-1 \mathrm{~mm}$ & $0.25-0.5 \mathrm{~mm}$ & $<0.25 \mathrm{~mm}$ \\
\hline 0 & 33.63 & 22.14 & 11.53 & 7.81 & 13.76 & 13.12 \\
1 & 9.72 & 22.92 & 17.12 & 13.74 & 16.49 & 23.13 \\
2 & 6.86 & 16.03 & 15.88 & 19.22 & 20.22 & 25.52 \\
5 & 3.07 & 5.93 & 15.91 & 26.32 & 23.79 & 32.06 \\
10 & 0.25 & 2.29 & 11.69 & 29.92 & & \\
\hline
\end{tabular}

(Degens and Sparling, 1995). Unfortunately, the results of this research are unable to distinguish.

The aggregates in the diameter of $1-2 \mathrm{~mm}$ are in the dynamic equilibrium state between the two reverse processes. It can also be seen from Fig. $5 \mathrm{~b}$ that the proportions of water- stable aggregates in the size range of $0.5-1 \mathrm{~mm}, 0.25-0.5 \mathrm{~mm}$ and $<0.25 \mathrm{~mm}$ increase with the increase of the drying-wetting cycles mainly due to the breakdown of the aggregates with the greater sizes. In the initial 1-2 cycles, the proportions increase sharply and then slow down to be stable. During the dryingwetting cycles, the supplement from the breakdown of larger aggregates holds the dominant position.

Figure 6a shows the variations of the mean weight diameter (MWD) and geometric mean diameter (GMD) with the drying-wetting cycles. It can be seen that the MWD and GMD reduce in the logarithmic form with the increase of drying-wetting cycles. In the violent breakdown period, the reduction trends are obvious and then tend to be stable. In the first cycle, MWD and GMD both drop by $50 \%$. After 10 times of drying-wetting cycles, the MWD and GMD remain only $1 / 6$ and $1 / 4$ of the initial values. The stable state of the trend after 10 times cycles indicates that the refinement of water-stable aggregates caused by drying-wetting cycles will not go on endlessly but will be restricted by the ultimate cementation stress inside the aggregates.

Figure $6 \mathrm{~b}$ shows the proportion of water-stable aggregates with the diameter greater than $5 \mathrm{~mm}\left(W S A_{5}\right)$ and $0.25 \mathrm{~mm}\left(W S A_{0.25}\right)$ under the drying-wetting cycles. The variations of the corresponding slaking ratio of water-stable aggregates with the diameter greater than $5 \mathrm{~mm}\left(S R_{5}\right)$ and $0.25 \mathrm{~mm}\left(S R_{0.25}\right)$ are also illustrated.
The figure directly shows that the drying-wetting cycles cause the breakdown of soil aggregates gradually. The proportions of $W S A_{5}$ and $W S A_{0.25}$ reduce in the logarithmic form with the increase of drying-wetting cycles, and $S R_{5}$ and $S R_{0.25}$ increase in the logarithmic form with the increase of drying-wetting cycles accordingly. After 10 times of cycles, there are almostly no aggregates larger than $5 \mathrm{~mm}$ remained. The results show that the water stability of soil aggregates has been weakened with the increase of drying-wetting cycles. The more the drying-wetting cycles are, the higher the slaking ratio of water-stable aggregates is and the less the larger waterstable aggregates are.

The breakdown degree of water-stable aggregates by exogenic actions has a significant effect on corrosion resistance of earths. Generally, the breakdown mechanism of water-stable aggregates are as follows: the degrees of water intruding into the pores or cracks are unbalanced, making the thickening speed of diffusion layer among the particles and the condition of repulsive force exceeding the suction to be unbalanced. These unbalance stress relationships will furtherly cause the stress concentration. The breakdown will occur in the surface with the maximum difference between the repulsive force and van der Waals attractive force (Chinchalikar et al., 2012; McBride and Baveye, 2002). Hu et al. (2015) suggested two steps in aggregate breakdown when dried aggregates were re-wetted: (1) separating soil particles in aggregates to a distance of $1.2-1.4 \mathrm{~nm}$ between two adjacent particle surfaces by the surface hydration forces (the repulsive force); (2) breaking soil aggregates in a way of explosion or dispersion when the repulsive force was greater than the attractive force.

Table 3 Characteristic parameters of soil aggregates under drying-wetting cycles

\begin{tabular}{|c|c|c|c|c|c|c|}
\hline D-W cycles & $\mathrm{WSA}_{5} / \%$ & WSA $_{0.25} / \%$ & $\mathrm{SR}_{5} / \%$ & $\mathrm{SR}_{0.25} / \%$ & $\mathrm{MWD} / \mathrm{mm}$ & $\mathrm{GMD} / \mathrm{mm}$ \\
\hline 0 & 33.63 & 84.87 & 0.00 & 0.00 & 3.584 & 1.766 \\
\hline 1 & 9.72 & 76.61 & 71.10 & 9.73 & 1.969 & 0.903 \\
\hline 2 & 6.86 & 74.48 & 79.60 & 12.24 & 1.552 & 0.709 \\
\hline 5 & 3.07 & 71.44 & 90.87 & 15.82 & 0.985 & 0.513 \\
\hline 10 & 0.25 & 67.94 & 99.26 & 19.95 & 0.628 & 0.405 \\
\hline
\end{tabular}



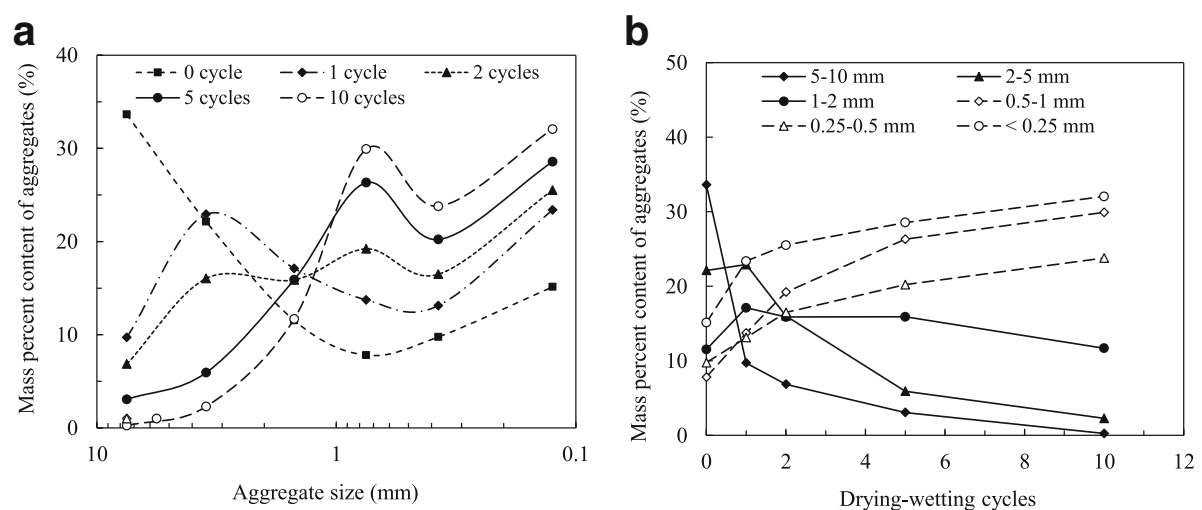

Fig. 5 (a) Size distribution of water-stable aggregates under drying-wetting cycles; (b) Mass percent content of soil aggregates in each size range under drying-wetting cycles

\section{Impact of initial water content}

The initial water content of soil, affected by climate, temperature and humidity, has important influence on the stability of aggregates and slope runoff. The initial water content correlates to the thickness of hydrated films surrounding the soil particles, namely the diffusion layer. The diffusion layer has a weakening effect on the suction among the soil particles, which means the increase of initial water content will weaken the matrix suction among the soil particles and reduce the infiltration of water. In addition, the diffusion layer will weaken the structural links among soil particles or micro-aggregates, causing the micro-aggregates to be more susceptible to external force. In addition, the increase of initial water content will decrease the effective void ratio, thereby narrowing the seepage space and weakening the intrusion effects.
By wet sieving method, the particle size distribution of water-stable aggregates after the breakdown of initial aggregates with different initial water content is listed in Table 4. The corresponding characteristic parameters of aggregates are listed in Table 5.

Figure 7a shows the size distribution of water-stable aggregates with the initial water content. For the initial water content of $5.08 \%, 14.51 \%$ and $24.73 \%$, the smaller the aggregate diameter is, the mass percent content the aggregates is. However for the initial water content of $29.68 \%$ and $37.52 \%$, there is a peak in the size range of $0.5-1 \mathrm{~mm}$. There exists a turning point in the diameter of approximately $0.3 \mathrm{~mm}$. For the aggregates with the diameter $>0.3 \mathrm{~mm}$, the contents of the water-stable aggregates increase with the increase of initial water content. By contrast, for the aggregates with the diameter $<0.3 \mathrm{~mm}$,
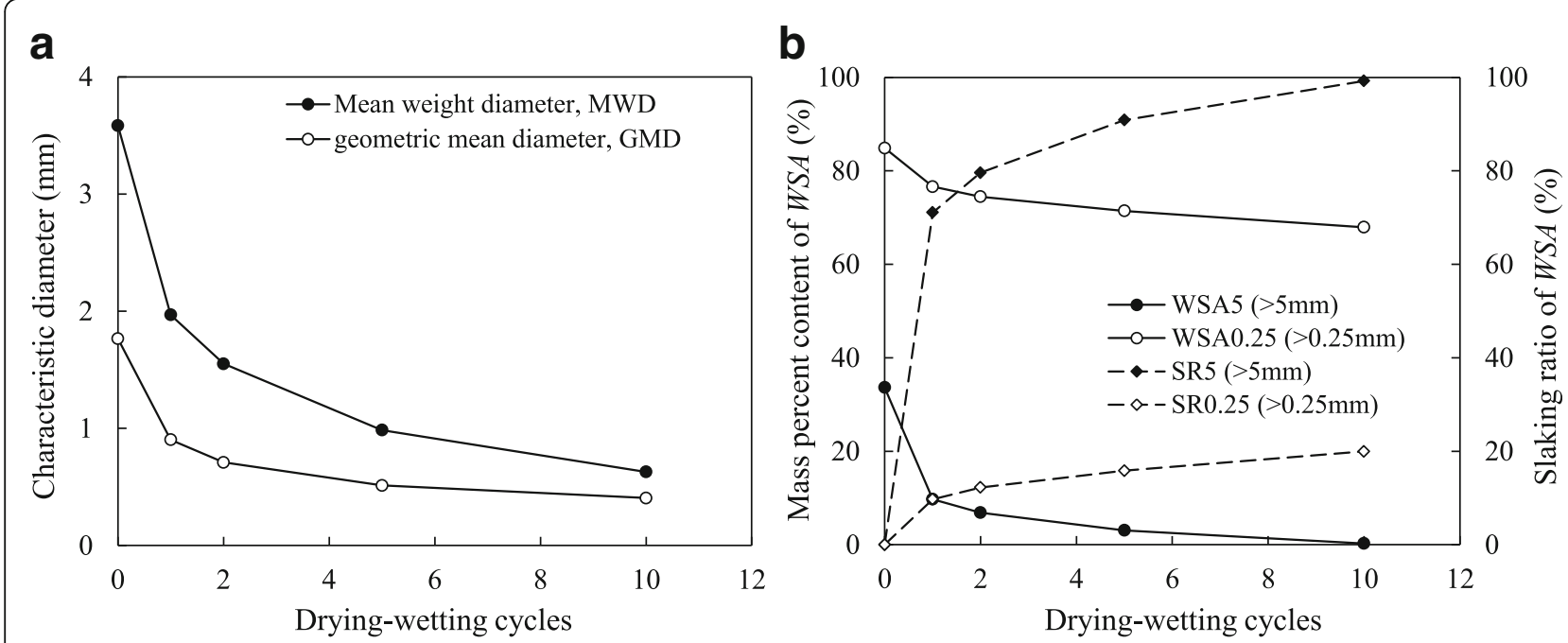

Fig. 6 (a) Characteristic diameters of water-stable aggregates under drying-wetting cycles; (b) variations of water stability and slaking ratio of water-stable aggregates 
Table 4 The distribution of grain size of soil aggregates under different initial water contents

\begin{tabular}{|c|c|c|c|c|c|c|}
\hline \multirow{2}{*}{$\begin{array}{l}\text { Initial water } \\
\text { content } w / \%\end{array}$} & \multicolumn{6}{|c|}{ Mass percent content of soil aggregates in each size range (\%) } \\
\hline & $5-10 \mathrm{~mm}$ & $2-5 \mathrm{~mm}$ & $1-2 \mathrm{~mm}$ & $0.5-1 \mathrm{~mm}$ & $0.25-0.5 \mathrm{~mm}$ & $<0.25 \mathrm{~mm}$ \\
\hline 5.08 & 0.00 & 0.00 & 0.74 & 3.32 & 4.17 & 91.77 \\
\hline 14.51 & 0.46 & 1.58 & 4.66 & 7.84 & 17.26 & 68.20 \\
\hline 24.73 & 1.23 & 4.89 & 12.67 & 16.28 & 20.25 & 44.68 \\
\hline 29.68 & 1.90 & 5.20 & 15.82 & 23.89 & 17.52 & 35.67 \\
\hline 37.52 & 3.07 & 5.93 & 15.91 & 26.32 & 20.22 & 28.56 \\
\hline
\end{tabular}

the contents of the water-stable aggregates decrease with the increase of initial water content. Figure $7 \mathrm{~b}$ shows the mass percent content of soil aggregates in each size range with the variations of initial water content. It can be seen from the figure that in the soils circularly dried and wetted, the water-stable aggregates with the size smaller than $2 \mathrm{~mm}$ play the predominant role. We try to explore the effect of initial water content on the distribution of predominate aggregates. We define the criterion that if the mass percent content of smaller aggregates $(<0.25 \mathrm{~mm})$ is greater than the sum of the mass percent content of medium aggregates $(0.25-1 \mathrm{~mm})$, the soil can be viewed as predominantly composed by smaller aggregates. By this criterion, a hypothesis has been introduced from the figure that for any given soil composition and physical environment history, there is a critical water content (about 24\%). Soils which have the initial water content less than the critical water content are predominantly composed by smaller aggregates. However, when the initial water content is greater than the critical water content, the soils are predominated by the medium aggregates.

After the breakdown of the soil aggregates by wet sieving, the variations of MWD and GMD with the initial water content are showed in Fig. 8a. It can be seen from the figure that MWD and GMD increase with the initial water content in the form of quadratic polynomial. When the initial water content is less than $10 \%$, the variations of MWD and GMD with the initial water content are unobvious. When $w>10 \%$, the characteristic diameters increase with a higher speed. The higher the initial water content is, the MWD and GMD of the residual water-stable aggregates are greater.
After wet sieving, the proportions of water-stable aggregates with the grain size greater than $5 \mathrm{~mm}\left(W S A_{5}\right)$ and $0.25 \mathrm{~mm}\left(W S A_{0.25}\right)$ with the initial water content are illustrated in Fig. 8b. The variations of the corresponding slaking ratio of water-stable aggregates with the diameter greater than $5 \mathrm{~mm}\left(S R_{5}\right)$ and $0.25 \mathrm{~mm}\left(S R_{0.25}\right)$ are also illustrated. The proportions of $W S A_{5}$ and $W S A_{0.25}$ increase linear with the increase of initial water content, and $S R_{5}$ and $S R_{0.25}$ increase linearly with the increase of initial water content accordingly. The results show that the water stability of soil aggregates enhances with the increase of initial water content. The increase of initial water content can obviously strengthen the resistance ability of soil aggregates on rainfall and runoff erosion, reducing the degree of disintegration of aggregates.

\section{Mathematical model to estimate leakage ratio}

After the drying and rewetting by the runoffs, the original aggregates undergo the following breakdown and movement: (a) the original aggregates crack into smaller ones or reunite to larger ones; (b) water-unstable aggregates are dissolved and washed away by runoffs; (c) the water-stable aggregates have the possible to leak through the karst channels by the hydraulic forces (Fig. 9).

The size distribution of water-stable aggregates after breakdown in procedure (a) can be symbolized as follow:

$$
f\left(d_{i}\right) \in\left\{P_{d_{i}} \mid d_{i} \in\{7.5, \quad 3.5, \quad 1.5,0.75,0.375,0.125\}\right\}
$$

where, $P_{d_{i}}$ is the mass percent content of the waterstable aggregates with the diameter of $d_{\mathrm{i}}$. The probability

Table 5 Characteristic parameters of soil aggregates under different initial water contents

\begin{tabular}{lllllll}
\hline Initial water content $W / \%$ & $\mathrm{WSA}_{5} / \%$ & $\mathrm{WSA}_{0.25} / \%$ & $\mathrm{SR}_{5} / \%$ & $\mathrm{SR}_{0.25} / \%$ & $\mathrm{MWD} / \mathrm{mm}$ & $\mathrm{GMD} / \mathrm{mm}$ \\
\hline 5.08 & 0.00 & 8.23 & 100.00 & 90.30 & 0.174 & 0.140 \\
14.51 & 0.46 & 31.80 & 98.39 & 61.68 & 0.382 & 0.184 \\
24.73 & 1.23 & 55.32 & 95.69 & 30.12 & 0.791 & 0.346 \\
29.68 & 1.90 & 64.33 & 93.32 & 22.18 & 0.913 & 0.428 \\
37.52 & 3.07 & 71.44 & 90.87 & 15.82 & 0.985 & 0.513 \\
\hline
\end{tabular}



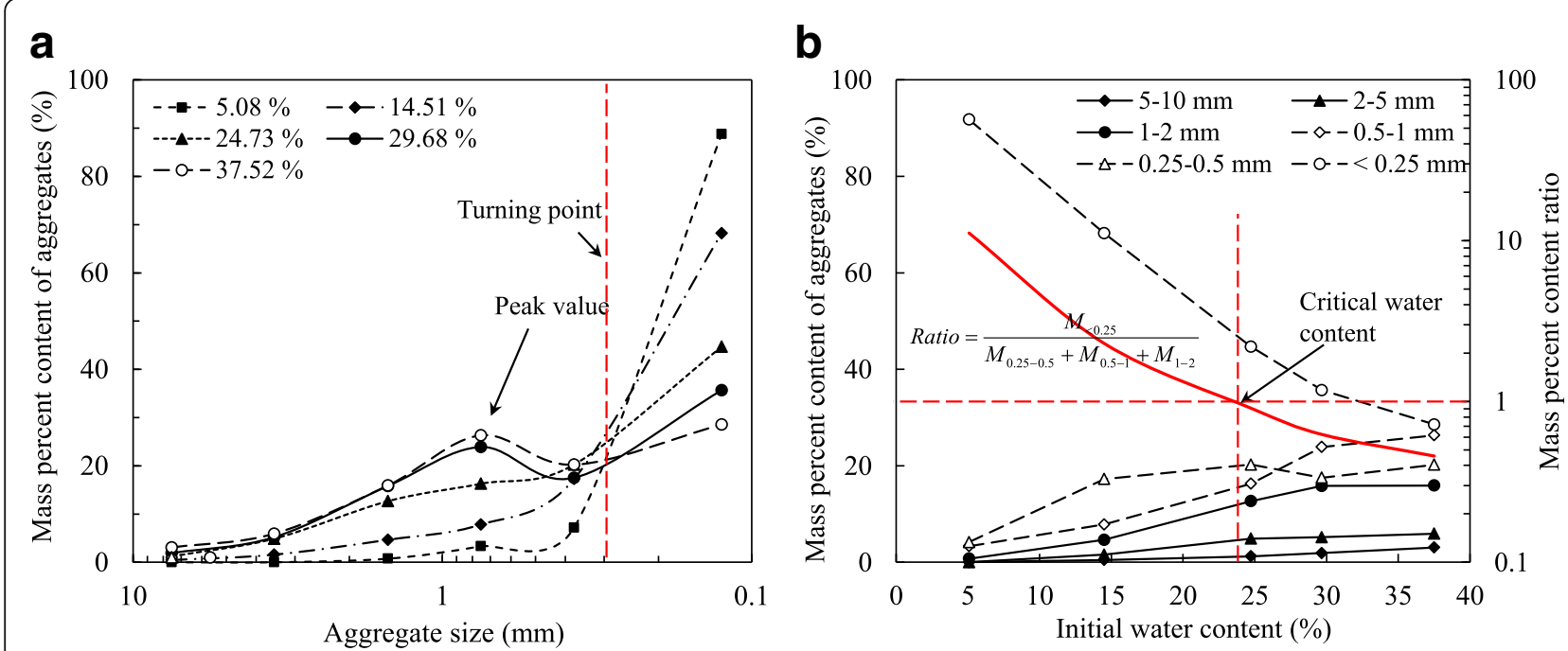

Fig. 7 (a) Size distribution of water-stable aggregates with different initial water content; (b) Mass percent content of soil aggregates in each size range

$\eta$ of the water-stable aggregates with a diameter of $d_{i}$ being eroded through the leakage channel can be defined as Eq. (8).

$$
\eta \propto 1 / d_{i}^{2}
$$

Thus, the relative leakage ratio $(R)$ can be evaluated by Eq. (9).

$$
R=\eta f\left(d_{i}\right)
$$

Selecting the specimen with $5.08 \%$ initial water content after 5 drying-wetting cycles as the reference, the normalized relative leakage ratios are illustrated in Fig. 10.

Analyzed from the data, the relative leakage ratio $\left(R_{1}\right)$ with the drying-wetting cycles $(N)$ can be fitted as follow:

$$
R_{1}=\frac{N^{c}}{a+b N^{c}}
$$

where, $a$ means the difficulty level of the initial cycle increasing the relative leakage ratio; $b$ means the ultimate leakage ratio with the increase of drying-wetting cycles; $c$ means the rate of rise of the relative leakage ratio. In
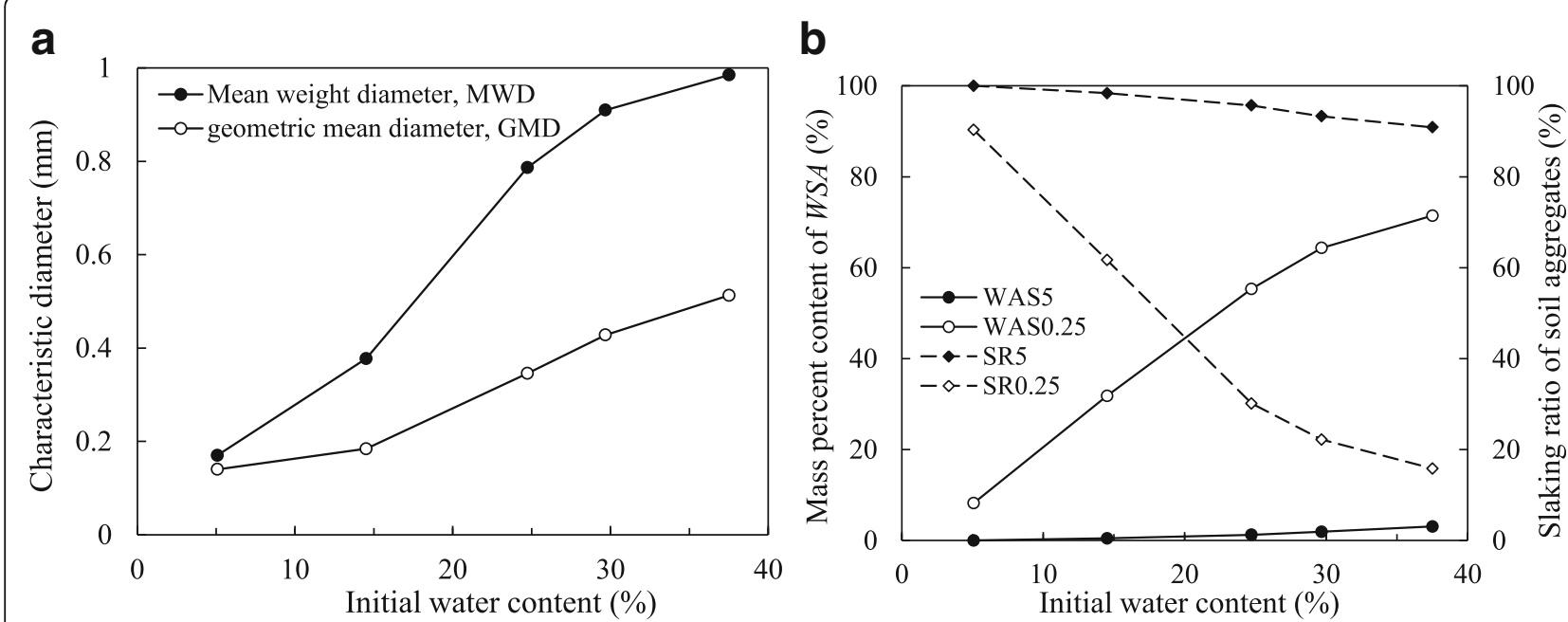

Fig. 8 (a) Characteristic diameters of soil aggregates; (b) variations of water stability and slaking ratio of water stable aggregates under different initial water contents 


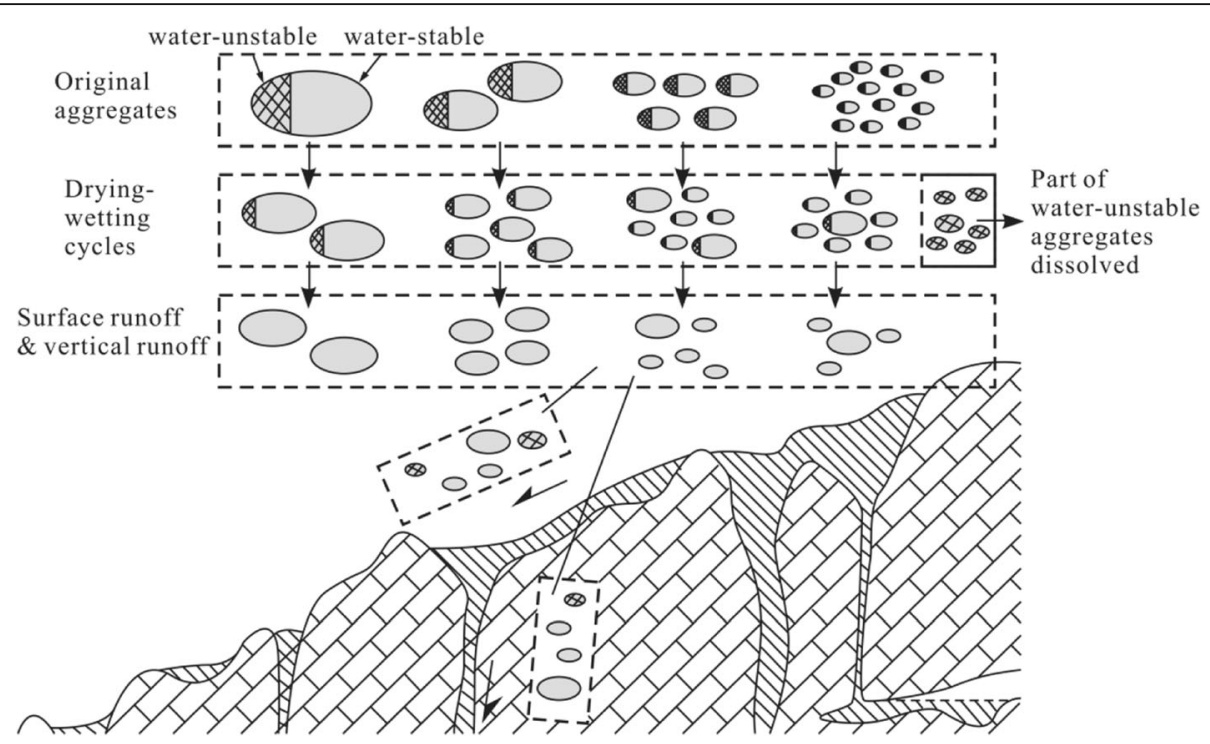

Fig. 9 Breakdown and leakage model for the aggregates in karst areas

this research, $a$ equals to $9.7737 ; b$ equals to $0.5599 ; c$ equals to 0.3574 .

The relationship between the relative leakage ratio $\left(R_{2}\right)$ and initial water content $(w)$ can be fitted as follows:

$$
R_{2}= \begin{cases}A w+B & w<w_{\text {critical }} \\ C w+D & w>w_{\text {critical }}\end{cases}
$$

where, $w_{\text {critical }}$ is the critical water content, which is consistent to the value mentioned earlier and equals to $28 \%$ approximately; A, B, C and D are the parameters equal to $-0.0247,1.1239,-0.0093$ and 0.6922 respectively.

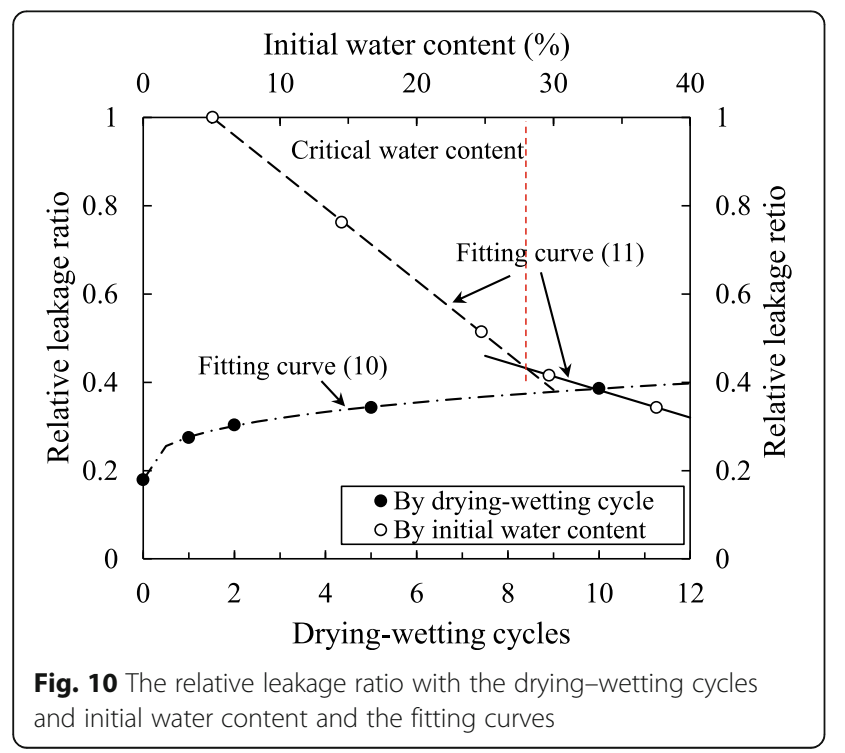

\section{Conclusions}

In general, our results suggest that the drying-wetting cycles cause a significant aggregate slaking, especially within the first two cycles. However, the extent of the slaking process is significantly reduced with repeated drying-wetting cycles, showing that most aggregates become more slacking resistant. The variation curves of the proportion of water-stable aggregates with the size 1-5 mm firstly increase by drying and wetting to a maximum value and then decrease, showing a coexistence of slaking process and supplement.

We have found that there exists the critical water content (about 24\%), with the initial water content less than the critical value soils are predominantly composed by smaller aggregates. A turning point has also been obtained that the contents of the water-stable aggregates larger than $0.3 \mathrm{~mm}$ increase with the increase of initial water content. Overall, the increase of initial water content strengths the water stability.

The mathematical model for the relative leakage ratio based on the drying-wetting cycles, the initial water content and the size distribution of water-stable aggregates may help propose more precise leakage model of loams in karst areas to assess the leakage potential. Further investigations are required to consider more reasonable match between the drying-wetting cycles in the tests and in practice, especially in the frequency and intensity.

\section{Acknowledgements}

The work presented in this paper was supported by the National Natural Science Foundation of China (Grant No. 41572285).

\section{Authors' contributions}

The work presented here was carried out in collaboration between all authors. TYQ, ZJ and XJ defined the research theme. XJ and ZJ designed 
methods and experiments, performed the statistical analysis, analyzed the data and interpreted the results. XJ and ZJ co-worked on conceived of the study, and participated in its design and coordination and helped to draft the manuscript, associated data collection and their interpretation. All authors revised and approved the final version of the manuscript.

\section{Competing interests}

The authors declare that they have no competing interests.

\section{Publisher's Note}

Springer Nature remains neutral with regard to jurisdictional claims in published maps and institutional affiliations.

Received: 20 April 2017 Accepted: 7 September 2017

Published online: 15 September 2017

\section{References}

Amezketa, E. 1999. Soil aggregate stability: A review. Journal of Sustainable Agriculture 14 (2-3): 83-151.

An, J., F. Zheng, J. Lu, and G. Li. 2012. Investigating the role of raindrop impact on hydrodynamic mechanism of soil erosion under simulated rainfall conditions. Soil Science 177 (8): 517-526.

Bartlová, J., B. Badalíková, L. Ospíšilová, E. Pokorný, and B. Šarapatka. 2015. Water stability of soil aggregates in different systems of tillage. Soil \& Water Research 10: 147-154.

Chen, M., C. Yan, Y. Wang, Q. Zhan, J. Wan, J. Zheng, G.H. Guo, and X. Chen. 2010. Environmental significance of clay minerals and its influence to the soil permeability - A case study of puding county, guizhou province. Geol Rev 156 (5): 180-187 (in Chinese).

Chinchalikar, A.J., V.K. Aswal, J. Kohlbrecher, and A.G. Wagh. 2012. Evolution of structure and interaction during aggregation of silica nanoparticles in aqueous electrolyte solution. Chemical Physics Letters 542: 74-80.

Dagesse, D.F. 2012. Freezing cycle effects on water stability of soil aggregates. Canadian Journal of Soil Science 93 (4): 473-483.

de Paz, J.M., J. Sánchez, and F. Visconti. 2006. Combined use of GIS and environmental indicators for assessment of chemical, physical and biological soil degradation in a Spanish Mediterranean region. Journal of Environmental Management 79 (2): 150.

Degens, B.P., and G.P. Sparling. 1995. Repeated wet-dry cycles do not accelerate the mineralization of organic $\mathrm{C}$ involved in the macro-aggregation of a sandy loam soil. Plant and Soil 175 (2): 197-203.

Denef, K., J. Six, H. Bossuyt, S.D. Frey, E.T. Elliott, R. Merckx, and K. Paustian. 2001a. Influence of dry-wet cycles on the interrelationship between aggregate, particulate organic matter, and microbial community dynamics. Soil Biology and Biochemistry 3: 1599-1611.

Denef, K., J. Six, K. Paustian, and R. Merckx. 2001b. Importance of macroaggregate dynamics in controlling soil carbon stabilization: Shortterm effects of physical disturbance induced by dry-wet cycles. Soil Biology and Biochemistry 33: $2145-2153$

Domżł, H., J. Hodara, A. Słowińska-Jurkiewicz, and R. Turski. 1993. The effects of agricultural use on the structure and physical properties of three soil types. Soil and Tillage Research 27 (1-4): 365-382.

Duiker, S.W., D.C. Flanagan, and R. Lal. 2001. Erodibility and infiltration characteristics of five major soils of southwest Spain. Catena 45: 103-121.

Febles-González, J.M., M.B. Vega-Carreño, A. Tolón-Becerra, and X. Lastra-Bravo. 2012. Assessment of soil erosion in karst regions of havana, cuba. Land Degradation and Development 23 (5): 465-474.

Feeser, I., and M. O'Connell. 2009. Fresh insights into long-term changes in flora, vegetation, land use and soil erosion in the karstic environment of the burren, western ireland. Journal of Ecology 97 (5): 1083-1100.

Figueiredo, M.D.A., C.H.R.R. Augustin, and J.D. Fabris. 1999. Mineralogy, size, morphology and porosity of aggregates and their relationship with soil susceptibility to water erosion. Hyperfine Interactions 122 (1-2): 177-184.

Foster, G.R. 1982. Evaluation of rainfall-runoff erosivity factors for individual storms. Transactions of ASAE 25: 124

Fujiwara, T., and A. Yamamoto. 1981. Mechanism of soil erosion under simulated rainfall: Erosion by runoff. Memoirs of the Faculty of Engineering Yamaguchi University 32: 119-126.

Gao, H., and R. Li. 2007. Erodibility of original soil in karst area. Science of Soil and Water Conservation 5 (6): 1-7 (in Chinese).
Gardner, W.R. 1956. Representation of soil aggregate-size distribution by a logarithmic-normal distribution. Soil Science Society of America Journal 20 (2): 151-153.

Hofman, G. 1976. The influence of drying and storing soil samples on aggregate instability. Mededelingen van de Faculteit landbouwwetenschappen Rijksuniversiteit Gent 41: 101-108.

Hogarth, W.L., C.W. Rose, J.Y. Parlange, G.C. Sander, and G. Carey. 2004. Soil erosion due to rainfall impact with no inflow: A numerical solution with spatial and temporal effects of sediment settling velocity characteristics. Journal of Hydrology 295 (1): 140-148.

Hu, F.N., C.Y. Xu, H. Li, S. Li, Z.H. Yu, Y. Li, and X.H. He. 2015. Particles interaction forces and their effects on soil aggregates breakdown. Soil and Tillage Research 147 (5): 1-9.

Igwe, C.A., F.O.R. Akamigbo, and J.S.C. Mbagwu. 1995. The use of some soil aggregate indices to assess potential soil loss in soils of south-eastern nigeria. International Agrophysics 9 (2): 95-100.

Jankauskas, B., G. Jankauskienè, and M.A. Fullen. 2008. Soil erosion and changes in the physical properties of Lithuanian Eutric Albeluvisols under different land use systems. Acta Agriculturae Scandinavica 58 (1): 66-76.

Jastrow, J.D., and R.M. Miller. 1991. Methods for assessing the effects of biota on soil structure. Agriculture, Ecosystems \& Environment 34: 279-303.

Jozefaciuk, G., and H. Czachor. 2014. Impact of organic matter, iron oxides, alumina, silica and drying on mechanical and water stability of artificial soil aggregates. Assessment of new method to study water stability. Geoderma 221-222 (6): 1-10.

Kemper, W.D., R. Rosenau, and S. Nelson. 1985. Gas displacement and aggregate stability of soil. Soil Science Society of America Journal 49: 25-28.

Kheir, R.B., C. Abdallah, and M. Khawlie. 2008. Assessing soil erosion in mediterranean karst landscapes of lebanon using remote sensing and GIS. Engineering Geology 99 (3-4): 239-254.

Lal, R. 2003. Soil erosion and the global carbon budget. Environment International 29 (4): 437-450.

McBride, M.B., and P. Baveye. 2002. Diffuse double-layer models, long-range forces, and ordering in clay colloids. Soil Science Society of America Journal 66: 1207-1217

Nearing, M.A., L.J. Lane, E.E. Alberts, and J.M. Laflen. 1990. Prediction technology for soil erosion by water-status and research needs. Soil Science Society of America Journal 54 (6): 1702-1711.

Olson, T.C., and W.H. Wischmeier. 1963. Soil erodibility evaluations for soils on the runoff and erosion stations. Soil Science Society of America Proceedings 27 (5): 590-592.

Owoputi, L.O. 1994. A physically-based study of the mechanism of sediment detachment in the soil erosion process. Saskatchewan, Canada: University of Saskatchewan.

Parlange, J.-Y., W.L. Hogarth, B.C.P. Heng, G.C. Ser, D.A. Barry, A. Brovelli, S. Jomaa, M.B. Parlange, P.B. Hairsine, T.S. Steenhuis, H.J. van Meerveld, and C.W. Rose 2012. Erosion of soils due to rainfall impact-an interpolation method. Ecohydrology 5 (5): 575-579

Peng, X., R. Horn, and A. Smucker. 2007. Pore shrinkage dependency of inorganic and organic soils on wetting and drying cycles. Soil Science Society of America Journal 71: 1095-1104.

Pires, L.F., O.O.S. Bacchi, and K. Reichardt. 2007. Assessment of soil structure repai due to wetting and drying cycles through 2D tomographic image analysis. Soil and Tillage Research 94 (2): 537-545.

Reichert, J.M., L.D. Norton, N. Favaretto, C.H. Huang, and E. Blume. 2009. Settling velocity, aggregate stability, and interrill erodibility of soils varying in clay mineralogy. Soil Science Society of America Journal 73 (4): 1369-1377.

Rose, C.W., J.R. Williams, and G.C. Sander. 1983. A mathematical model of soil erosion and deposition processes: I. Theory for a plane land element. Soil Science Society of America Journal 47 (5): 991-995.

Rouhipour, H., H. Ghadiri, and C.W. Rose. 2006. Investigation of the interaction between flow-driven and rainfall-driven erosion processes. Australian Journal of Soil Research 44 (5): 503-514.

Shelton, I.J., and G.J. Wall. 1998. Indicator of risk of soil degradation: Erosion component the risk of soil erosion in Canada.

Smith, R.E., C. Corradini, and F. Melone. 1999. A conceptual model for infiltration and redistribution in crusted soils. Water Resources Research 35 (35): 1385-1393.

Soulides, D.A., and F.E. Allison. 1961. Effect of drying and freezing soils on carbon dioxide production, available minerat nutrients, aggregation and bacterial population. Soil Science 91: 291-298. 
Sweeting, M.M. 1973. Karst Landforms. New York, NY: Columbia University Press. Tabeda, Y., and M. Tomita. 1972. Study of the mechanism of soil erosion. Nogyo Doboku Gakkai Trans: II. The relation between soil erosion and rainfall intensity based on the energy of raindrops.

Tang, Q., Y. Xu, S.J. Bennett, and Y. Li. 2015. Assessment of soil erosion using RUSLE and GIS: A case study of the yangou watershed in the loess plateau, china. Environment and Earth Science 73 (4): 1715-1724.

Tisdall, J.M., B. Cockroft, and N.C. Uren. 1978. The stability of soil aggregates as affected by organic materials, microbial activity and physical disruption. Soil Research 16 (1): 9-17.

Utomo, W.H., and A.R. Dexter. 1982. Changes in soil aggregate water stability induced by wetting and drying cycles in non-saturated soil. European Journal of Soil Science 33 (4): 623-637.

Van Bavel, C.H.M. 1949. Mean weight diameter of soil aggregates as a statistical index of aggregation. Soil Science Society of America Proceedings 14: 20-23.

Walker, J.D., M.T. Walter, J.-Y. Parlange, C.W. Rose, H.J. Tromp-van Meerveld, B. Gao, and A.M. Cohen. 2007. Reduced rain-drop impact driven soil erosion by infiltration. Journal of hydrology 342 (3-4): 331-335.

Wang, S.J., Q.M. Liu, and D.F. Zhang. 2004. Karst rocky desertification in southwestern China: Geomorphology, land use, impact and rehabilitation. Land Degradation and Development 15 (2): 115-121.

Ye, W.M., Z.Y. Qi, B. Chen, J. Xie, Y. Huang, Y.R. Lu, and Y.J. Cui. 2011. Mechanism of cultivation soil degradation in rocky desertification areas under dry/wet cycles. Environment and Earth Science 64 (1): 269-276.

Yoder, R.E. 1936. A direct method of aggregate analysis of soils and a study of the physical nature of erosion losses. J Am Soc Agron 28 (5): 337-351.

Yuan, D.X. 1996. Southwest karst mountain environmental geological problems in our country. Explor Nat 15 (58): 21-23 (in Chinese).

\section{Submit your manuscript to a SpringerOpen ${ }^{\circ}$ journal and benefit from:}

- Convenient online submission

Rigorous peer review

- Open access: articles freely available online

- High visibility within the field

- Retaining the copyright to your article

Submit your next manuscript at $\gg$ springeropen.com 